\title{
TEORI KEAGENAN DAN MANAJEMEN LABA DARI SUDUT \\ PANDANG ETIKA MANAJER
}

\author{
Sri Luayyi \\ Universitas Brawijaya \\ Jl. Veteran Malang 65145 Indonesia
}

\begin{abstract}
This paper discuss about how agency theory in perspective attitude. If we clarify about agency theory so in discussing cannot separated with behavior of manager in doing earning management, because earning management is one of way that doing by manager in order to maintaining of achievement in front of principal in the most society consider that earning management is legality action, not harming another side and enabled (deed of manager heaving the character of positive), but in their action earning management is often to behavior of manager heaving the character of negative, here the problem is how the manager can differences among practice of earning management that bring the negative influence (it means that we must avoid) and how we can practicing earning management and bring it in positive influence (it means we can do it). In the general of main side of this paper is in the agency theory have explain about the relation between agent and principal. In the practice is manager as organizer of company will more known about the information internal and external related to present day company prospect and a period of come to be compared owner of company. So the information came to be the owner of company some time in appropriate within the fact of condition, that condition is familiar with term information asymmetry. In the information asymmetry both of them will giving opportunity for manager to do earning management.. Manager only will doing earning management that positive character if they have the good attitude, because basically manager that they have the good attitude always acting what conscience word so each every decision and step of will express ethical behavior.
\end{abstract}

Keywords : Agency Theory, Earning Management, Manager Attitude

Di dalam teori keagenan pada dasarnya membahas suatu bentuk kesepakatan antara pemilik modal dengan manajer untuk mengolah suatu perusahaan, di sini manajer mengemban tanggung jawab yang besar atas keberhasilan operasional perusahaan yang dikelolanya, jika dalam menjalankan amanah tersebut manajer gagal maka jabatan dan segala vasilitas yang 
diperolehnya menjadi taruhannya, alasan itulah yang sering kali mendasari mengapa manajer mau melakukan manajemen laba (yang bersifat negatif) yang semata-mata hanya ingin melindungi dirinya dan merugikan banyak pihak. Menurut Jensen dan Meckling (1976), dalam teori keagenan (agency theory), hubungan agensi muncul ketika satu orang atau lebih (principal) mempekerjakan orang lain (agent) untuk memberikan suatu jasa dan kemudian mendelegasikan wewenang dalam pengambilan keputusan kepada agent tersebut. Dalam prakteknya manajer sebagai pengelola perusahaan tentunya mengetahui lebih banyak informasi internal dan prospek perusahaan di waktu mendatang dibandingkan pemilik modal atau pemegang saham. Sehingga sebagai pengelola, manajer memiliki kewajiban memberikan informasi mengenai kondisi perusahaan kepada pemilik. Tetapi dalam hal ini informasi yang disampaikan oleh manajer terkadang tidak sesuai dengan kondisi perusahaan yang sebenarnya. Kondisi yang demikian dikenal sebagai informasi yang tidak simetris atau asimetri informasi (Wibisono, 2004). Dalam hal ini asimetri informasi antara manajemen (agent) dengan pemilik (principal) dapat memberikan kesempatan kepada manajer untuk melakukan manajemen laba (Richardson, 1998).

Tindakan manajemen laba (earnings management) ini telah memunculkan beberapa kasus skandal pelaporan akuntansi, salah satu contohnya adalah Enron sebuah kasus yang terjadi di Amerika, sedangkan contoh kasus yang terjadi di Indonesia seperti PT. Lippo Tbk dan PT. Kimia Farma Tbk yang berawal dari terdeteksinya manipulasi dalam pelaporan keuangan (Gideon, 2005). Sebenarnya semua kasus itu bisa saja dihindari jika perilaku manajer selalu berpegang pada etika dan norma-norma kemanusiaan. Dengan kata lain manajer yang memiliki 
perilaku etis akan lebih mudah dalam menghadapi permasalahan perusahaan. Teori keagenan memandang perusahaan sebagai nexus of contracts yaitu organisasi yang terikat kontrak dengan beberapa pihak, seperti kontrak dengan pemegang saham, supplier, karyawan (termasuk manajer) dan pihak-pihak lain yang terkait (Scott, 2000: ). Perusahaan juga memiliki ikatan kontrak dengan kreditur jika perusahaan tersebut melibatkan utang sebagai salah satu pendanaannya. Sebagian besar perusahaan menggunakan utang sebagai sumber pendanaan karena dapat meningkatkan kinerja manajer, dan jika kinerjanya meningkat maka pemegang saham akan bersedia membayar harga saham perusahaan lebih mahal (Jensen dan Meckling dalam Utama 2000). Hal-hal semacam itulah antara lain yang memotivasi manajer, sehingga dalam mengelola perusahaan melakukan praktik manajemen laba yang bersifat negatif, karena sebagai seorang agen idealnya dia mampu memuaskan pemilik modal dengan perolehan prestasi yang bagus (pencapaian laba yang optimum). Di sini moralitas seorang manajer diuji, apakah manajer mampu mengendalikan dirinya dengan tidak melakukan manajemen laba yang bersifat negatif dalam kondisi apapun. Jika dia termasuk manajer yang beretika, di mana dia selalu berpegang pada prinsipprinsip etika dalam menjalankan aktivitasnya, maka dia akan terhindar dari perbuatan yang tidak etis sehingga dia bisa dikatakan manajer yang jujur dan amanah, apa yang dilakukannya semata-mata untuk memuaskan kepentingan banyak pihak termasuk dirinya sendiri. Kalaupun seandainya dia mengalami kegagalan dalam menjalankan tanggungjawabnya, maka dia mampu menghadapinya dan siap menanggung segala bentuk resiko yang harus 
diterimanya asalkan apa yang telah dilakukannya telah berpegang pada nilai-nilai etika.

\section{PEMBAHASAN}

Banyak orang percaya bahwa perilaku etika dibentuk oleh prinsip-prinsip moral yang diberikan dalam agama. Dalam hal ini ada kode instruksi otoritatif mengenai bagaimana berperilaku. Sejarah menunjukkan bahwa di sebagian besar agama, dalam penentuan prinsip-prinsip ini menjadi subyek banyak perdebatan dan menghasilkan praktik-praktik yang kelihatannya (untuk pengamat luar) memiliki sedikit hubungan dengan perilaku moral, dan ketika menguji isu etika ada beberapa pertimbangan moral untuk bercermin.

Pengertian etika dalam bahasa latin ethica berarti falsafah moral. Ia merupakan pedoman cara bertingkah laku yang baik dari sudut pandang budaya, susila serta agama. Sedangkan menurut Keraf (1998: 10), etika secara harfiah berasal dari kata Yunani ethos (jamaknya: ta etha), yang artinya sama persis dengan moralitas, yaitu adat kebiasaan yang baik. Menurut PPPB (1998), istilah etika memiliki tiga arti, yang salah satunya adalah nilai mengenai benar dan salah yang dianut suatu golongan atau masyarakat. Dari beberapa definisi di atas dapat disimpulkan bahwa etika merupakan seperangkat aturan atau norma atau pedoman yang mengatur perilaku manusia, baik yang harus dilakukan maupun yang harus ditinggalkan, yang dianut oleh sekelompok atau segolongan manusia atau masyarakat atau profesi.

Menurut Keraf dan Sony (2001: ), etika dapat dibagi menjadi dua yaitu, Pertama, Etika umum. Etika umum berkaitan dengan bagaimana manusia 
mengambil keputusan etis, teori-teori etika dan prinsip-prinsip moral dasar yang menjadi pegangan bagi manusia dalam bertindak, serta tolok ukur dalam menilai baik atau buruknya suatu tindakan. Etika umum dapat dianalogkan dengan ilmu pengetahuan, yang membahas mengenai pengertian umum dan teori-teori.

Kedua, Etika khusus, Etika khusus adalah penerapan prinsip-prinsip moral dasar dalam bidang kehidupan yang khusus. Etika khusus dapat dibagi menjadi dua, yaitu: (a) Etika individual, yang menyangkut kewajiban dan sikap manusia terhadap dirinya sendiri. (b) Etika sosial, yang berkaitan dengan kewajiban, sikap, dan pola perilaku manusia dengan manusia lainnya, salah satu bagian dari etika sosial adalah etika profesi, dalam hal ini termasuk etika profesi akuntan.

Menurut Keraf dan Imam (1995:70-77) terdapat beberapa prinsip dalam etika bisnis yang meliputi : (1) Prinsip otonomi, Otonomi adalah sikap dan kemampuan manusia untuk bertindak berdasarkan kesadarannya sendiri tentang apa yang dianggapnya baik untuk dilakukan. Dalam prinsip otonomi ini terkait dua aspek yaitu aspek kebebasan dan aspek tanggung jawab. (2) Prinsip kejujuran. Aspek kejujuran dalam bisnis meliputi; kejujuran terwujud dalam pemenuhan syarat-syarat perjanjian dan kontrak. Kejujuran juga menemukan wujudnya dalam penawaran barang dan jasa dengan mutu yang baik, dan terakhir kejujuran menyangkut hubungan kerja dalam perusahaan.

Prinsip kejujuran ini sangat berkaitan dengan aspek kepercayaan. Kepercayaan ini merupakan modal dasar yang akan mengalirkan keuntungan yang besar di masa depan. (1) Prinsip tidak berbuat jahat dan prinsip berbuat baik. Prinsip ini memiliki dua bentuk yaitu prinsip berbuat baik menuntut agar secara aktif dan maksimal kita semua berbuat hal yang baik bagi orang lain dan dalam 
bentuk yang minimal dan pasif menuntut agar kita tidak berbuat jahat kepada orang lain. (2) Prinsip keadilan, Prinsip ini menuntut agar kita memperlakukan orang lain sesuai dengan haknya. Hak orang lain perlu dihargai dan jangan sampai dilanggar. (3) Prinsip hormat pada diri sendiri, Sebenarnya dalam arti tertentu prinsip ini sudah tercakup dalam prinsip pertama dan prinsip kedua di atas. Prinsip ini sengaja dirumuskan secara khusus untuk menunjukkan bahwa setiap individu itu mempunyai kewajiban moral yang sama bobotnya untuk menghargai diri sendiri.

Menurut Siagian (1996: ), bahwa setidaknya ada empat alasan mengapa mempelajari etika itu sangat penting, karena; (a) etika memandu manusia dalam memilih berbagai keputusan yang dihadapi dalam kehidupan. (b) etika merupakan pola perilaku yang didasarkan pada kesepakatan nilai-nilai sehingga kehidupan yang harmonis dapat tercapai. (c) dinamika dalam kehidupan manusia menyebabkan perubahan nilai-nilai moral sehingga perlu dilakukan analisa dan ditinjau ulang. (d) etika mendorong tumbuhnya naluri moralitas dan mengilhami manusia untuk sama-sama mencari, menemukan, dan menerapkan nilai-nilai hidup yang hakiki.

Menurut Rest (1986: ) proses perilaku etis memiliki tahapan sebagai berikut:

The person must be able to identify alternative actions and how those alternatives will effect the welfare of interested parties. 2. The person must be able to judge which course of action ought to be undertaken in that situation because it is morally right (or fair or just morally good). 3 . The person must intend to do what is morally right by giving priority to moral value above other personal values. 4. The person must have sufficient perseverance, ego strenght and implementation skills to be able to follow through on his/her intention to behave morally, to withstand fatigue and flagging will, and to overcome obstacles. 
Empat hal tersebut berkaitan dengan moral perception, moral judgement, moral intention, dan moral action. Moral perception dan moral judgement berkenaan dengan bagaimana seseorang memikirkan isu-isu etika dan bagaimana kedua hal tersebut menilai pengaruh eksternal dan internal terhadap pengambilan keputusan etis. Dengan demikian moral perception dan moral judgement berkaitan erat dengan intelektual (akal). Sedangkan dua hal yang terakhir yaitu moral intention dan moral action merupakan unsur psikologis dari diri manusia untuk berkehendak dalam berperilaku etis. Dengan kata lain, seseorang yang hanya memiliki moral perception dan moral judgement saja tidak dijamin untuk mampu berperilaku etis. Oleh karena itu harus diikuti oleh moral intention yang kemudian diaktualisasikan menjadi moral action.

Menurut Soewardi (2001:180-183) dalam usaha mencari atau menguasai ilmu, manusia dikaruniai Tuhan dengan perangkat rasio (akal) dan rasa (kalbu). Kemampuan rasio terletak pada membedakan, menyamakan, menggolongkan, menyatakan secara kuantitatif atau kualitatif, menyatakan hubungan-hubungan, dan mendeduksinya atau menginduksinya. Semua kemampuan rasio tersebut didasarkan pada ketentuan yang sudah baku dan rinci sehingga rasio tidak akan berdusta. Kemampuan rasa (kalbu) terletak pada kreativitas, yang merupakan kegaiban karena langsung berhubungan dengan Tuhan. Kreativitas inilah yang merupakan awal dari segala bidang nalar, ilmu, etika dan estetika. Etika dan estetika seluruhnya terletak pada rasa, sehingga jika manusia tidak punya rasa maka tidak ada etika dan estetika.

Seperti yang telah disinggung di atas menurut Jensen dan Meckling (1976), bahwa hubungan keagenan adalah sebuah kontrak antara manajer (agent) 
dengan investor (principal). Sehingga konflik kepentingan antara pemilik dan agen terjadi karena kemungkinan agen tidak selalu berbuat sesuai dengan kepentingan principal, yang kemudian memicu biaya keagenan (agency cost). Sebagai agen, manajer secara moral bertanggung jawab untuk mengoptimalkan keuntungan para pemilik (principal) dan sebagai imbalannya manajer akan memperoleh kompensasi sesuai dengan kontrak yang mereka sepakati. Dengan demikian terdapat dua kepentingan yang berbeda di dalam perusahaan, di mana masing-masing pihak berusaha untuk mencapai atau mempertahankan tingkat kemakmuran yang dikehendaki (Irfan, 2002). Sedangkan menurut Eisenhardt (1989), bahwa dalam teori agensi itu pada prinsipnya didasari tiga asumsi sifat manusia yaitu: (1) manusia pada umumya mementingkan diri sendiri (self interest). (2) manusia memiliki daya pikir terbatas mengenai persepsi masa mendatang (bounded rationality), dan (3) manusia selalu menghindari resiko (risk averse).

Dalam hal ini seperti yang telah disinggung di atas, bahwa manajer sebagai pengelola perusahaan lebih banyak mengetahui informasi internal dan prospek perusahaan di masa yang akan datang dibandingkan pemilik modal (pemegang saham). Sehingga manajer berkewajiban memberikan sinyal mengenai kondisi perusahaan kepada pemilik, dan sinyal yang diberikan dapat dilakukan melalui pengungkapan informasi akuntansi seperti laporan keuangan. Laporan keuangan tersebut penting bagi para pengguna eksternal karena kelompok ini berada dalam kondisi yang paling besar ketidakpastiannya (Irfan, 2002). Adanya ketidakseimbangan penguasaan informasi akan memicu munculnya suatu kondisi yang disebut sebagai asimetri informasi (information asymmetry). 
Asimetri antara manajemen (agent) dengan pemilik (principal) dapat memberikan kesempatan kepada manajer untuk melakukan manajemen laba (earnings management) dalam rangka menyesatkan pemilik (pemegang saham) mengenai kinerja ekonomi perusahaan. Disinilah naruni seorang manajer diuji untuk berperilaku dan mengontrol aktivitasnya, artinya setiap keputusan yang diambilnya berpegang pada norma-norma dan selalu memperhatikan kepentingan banyak orang dibanding kepentingannya sendiri (tidak bertindak egois). Berkaitan dengan ini perlu dibuat kode etik untuk manajer dalam menjalankan aktivitasnya yang disepakati untuk diterapkan dan dijadikan peraturan, yang jika tidak ditaati maka diadakan sanksi untuk pelanggaran tersebut.

Hal ini penting diterapkan dan bisa dipakai sebagai salah satu alat kontrol yang bisa digunakan untuk menjaga hubungan baik antara manajer dengan pemilik modal dalam hubungannya dalam teori keagenan. Sebagaimana yang telah dikatakan oleh Keraf (1998: ), Ada dua sasaran pokok dari kode etik, yaitu pertama, kode etik ini bermaksud untuk melindungi masyarakat dari kemungkinan dirugikan oleh kelalaian, baik secara sengaja maupun tidak sengaja dari kaum profesional. Kedua, kode etik ini bertujuan untuk melindungi keluhuran profesi tersebut dari perilaku-perilaku buruk orang-orang tertentu yang mengaku dirinya profesional.

Memang sebenarnya banyak cara bagaimana mengendalikan dan menjaga manajer agar tidak bertindak oportunis atau mementingkan keselamatan dirinya sendiri, salah satunya yang bisa dilakukan oleh pemilik modal adalah dengan pengawasan. Menurut Cornett et al. (2006), bahwa tindakan pengawasan oleh pihak investor dapat mendorong manajer untuk memfokuskan perhatiannya 
terhadap kinerja perusahaan, sehingga akan mengurangi perilaku oportunistik atau yang mementingkan dirinya sendiri. Tetapi hal itu memeliki kelemahan dalam pelaksanaannya, karena jika keinginan untuk berbuat oportunis itu sudah ada dibenak manajer maka pengawasan yang dilakukan sifatnya hanya bisa menekan tindakan tersebut. Berbeda dengan jika seorang manajer itu memiliki perilaku etika yang baik (setiap tindakannya mengacu pada norma-norma dan etika), maka kontrol itu datangnya dari dalam diri manajer itu sendiri (dari hati nuraninya) bukan dari luar atau dari orang lain, dan hal itu tentu akan lebih efektif dalam meminimalkan moral hazard yang ada pada diri seorang manajer bahkan bisa menghilangkannya.

Strategi manajemen laba dapat dibedakan menjadi manajemen laba artifisial dan manajemen laba transaksional (Stolowy \& Breton, 2000). Perusahaan melakukan manajemen laba artifisial melalui pemanfaatan fleksibilitas prinsip akuntansi dan pelanggaran prinsip akuntansi. Pemanfaatan fleksibilitas prinsip akuntansi meliputi praktik-praktik akuntansi yang konservatif, netral, dan agresif (Dechow \& Skinner, 2000). Manajemen laba transaksional merupakan praktik-praktik operasional atau penciptaan transaksi yang mempengaruhi laba dengan keterlibatan pihak eksternal, misalnya transaksi akuisisi, transaksi divestasi, dan transaksi dengan pihak-pihak dalam hubungan istimewa. Jadi, praktik manajemen laba dapat dikategorikan menjadi tiga yang meliputi fleksibilitas prinsip akuntansi, pelanggaran prinsip akuntansi, dan manajemen laba transaksional. 


\section{Fleksibilitas Prinsip Akuntansi}

Fleksibilitas ini meliputi (1) estimasi penyisihan piutang yang menimbulkan beban penyisihan piutang, konsisten dengan Beneish (1997) dan Dechow et al. (1995), (2) estimasi penyisihan persediaan menimbulkan beban penyisihan persediaan, konsisten dengan Beneish (1997), (3) estimasi umur aktiva atau tarif penyusutan menimbulkan beban penyusutan, konsisten dengan Neil et al. (1995) dan Michelson et al. (1995), dan (4) estimasi masa manfaat biaya tangguhan menimbulkan beban amortisasi biaya tangguhan, konsisten dengan Beneish (1997) dan Moses (1987). Perusahaan memiliki kebebasan untuk memperoleh keyakinan mengenai kewajaran beban-beban estimasian ini. Fleksibilitas pengestimasian penyisihan piutang dan penyisihan persediaan merupakan modus tertinggi dalam strategi manajemen laba.

\section{Pelanggaran Prinsip Akuntansi}

Pelanggaran prinsip akuntansi meliputi (1) tidak mencatat persediaan dalam proses untuk meningkatkan harga pokok penjualan, (2) tidak mencatat laba penjualan aktiva tetap, konsisten dengan Bartov (1993), (3) tidak mencatat kerugian penurunan nilai aktiva non operasi, konsisten dengan Copeland (1968), Schiff (1968), dan Kirchheimer (1968), (4) menggunakan nilai netto persediaan setelah dikurangi penyisihannya untuk menaikkan harga pokok penjualan, (5) mencatat investasi kepemilikan saham sebesar 20\% (lebih) dengan metode biaya, konsisten dengan Barefield dan Comiskey (1972) dan Dascher dan Malcolm (1970), (6) melaporkan goodwill negatif (selisih lebih nilai buku atas biaya perolehan investasi anak perusahaan) dengan masa amortisasi 20 tahun untuk 
menurunkan beban amortisasi; dalam hal ini, goodwill negatif seharusnya mengurangi biaya perolehan aktiva non lancar, (7) mencatat persediaan fiktif, konsisten dengan Beneish (1997); dalam hal ini, mencatat persediaan sebesar biaya upah, dan (8) membuat laporan menyesatkan tentang kerugian kehilangan persediaan, dengan tidak mengestimasi pendapatan dari klaim asuransi yang mengurangi kerugian.

\section{Manajemen Laba Transaksional}

Manajemen laba transaksional meliputi (1) kerugian selisih kurs akibat pembelian impor dalam valuta asing, konsisten dengan Brayshawand et al. (1989), (2) akuisisi perusahaan lain yang profitable atau divestasi anak perusahaan yang menderita kerugian, konsisten dengan Beneish (1999), (3) pencatatan pendapatan dan harga pokok penjualan fiktif dalam pengakuan pendapatan komisi sebagai perantara penjualan, (4) penyesatan pelaporan transaksi antar perusahaan atau antar pihak dalam hubungan istimewa; dalam hal ini, bentuk-bentuk transaksinya antara lain (a) membuat perjanjian pengalihan aktiva di masa depan dan bersifat kontinjensi untuk mengakui keuntungan atau kerugian saat menjelang akhir tahun, konsisten dengan Givoly dan Ronen (1981), (b) bertransaksi dengan perusahaan non publik yang terindikasi sebagai perusahaan afiliasi dalam pengendalian holding company, konsisten dengan Beneish (1997), Carlson dan Bathala (1997), serta Beattie et al. (1994), (c) bertransaksi penjualan dan pembelian, berutang, dan berpiutang, serta menyewa dan menyewakan ruang dengan perusahaan lain yang terindikasi sebagai perusahaan afiliasi dalam 
pengendalian holding company (mengindikasikan substansi ekonomi riil sebagai satu kesatuan entitas usaha).

Praktik penggeseran pendapatan dan beban antar perusahaan merupakan strategi manajemen laba yang sangat mungkin dilakukan secara luas oleh perusahaan publik di Indonesia. Praktik penggeseran pendapatan dan beban antar perusahaan merupakan strategi manajemen laba yang sangat mungkin dilakukan secara luas oleh perusahaan publik di Indonesia. Claessens et al. (2000) menyatakan bahwa pengelolaan perusahaan di Indonesia terpengaruh konsentrasi kepemilikan saham keluarga pendiri. Pendapat ini menguatkan dugaan bahwa perusahaan-perusahaan di Indonesia melakukan manajemen laba antar perusahaan dalam satu grup bisnis yang dikendalikan keluarga pendiri.

Berbicara tentang manajemen laba, merupakan salah satu hal yang bisa dilakukan seorang manajer dalam rangka menyelamatkan dirinya sendiri dari kedudukannya. menurut Schipper (1989), manajemen laba merupakan suatu intervensi dengan maksud tertentu terhadap proses pelaporan keuangan eksternal dengan sengaja untuk memperoleh beberapa keuntungan pribadi. Menurut Fischer dan Rosenzweig (1995), manajemen laba merupakan tindakan manajer untuk meningkatkan (menurunkan) laba yang dilaporkan saat ini dari suatu unit yang menjadi tanggung jawab manajer tanpa mengkaitkan dengan peningkatan (penurunan) profitabilitas ekonomi jangka panjang.

Manajemen laba dilakukan oleh manajer pada faktor-faktor fundamental perusahaan, yaitu dengan intervensi pada penyusunan laporan keuangan berdasarkan akuntansi akrual. Padahal kinerja fundamental perusahaan tersebut digunakan oleh pemodal untuk menilai prospek perusahaan, yang tercermin pada 
kinerja saham. Manajemen laba yang dilakukan manajer pada laporan keuangan tersebut akan mempengaruhi kinerja keuangan perusahaan, yang selanjutnya akan mempengaruhi kinerja saham (Wibisono, 2004). Brayshaw et al. (1989) menemukan bukti bahwa alasan manajemen melakukan manajemen laba adalah: (1) skema kompensasi manajemen yang dihubungkan dengan kinerja perusahaan yang disajikan dalam laba akuntansi yang dilaporkan; serta (2) fluktuasi dalam kinerja manajemen dapat mengakibatkan intervensi pemilik untuk mengganti manajemen dengan pengambilalihan secara langsung.

\section{KESIMPULAN}

Dari paparan di atas dapat penulis simpulkan bahwa sebenarnya banyak cara agar dalam menjalankan aktivitasnya manajer bertindak wajar (tidak bertentangan dengan etika yang ada) dan tidak melakukan hal-hal menyimpang yang bisa merugikan pihak lain sementara hanya dirinya sendiri yang diuntungkan. Atau banyak cara untuk menghindarkan seorang manajer dari tindakan moral hazard. Perilaku etis dalam aktivitas manajer sebenarnya bisa dijadikan sebagai pengendali utama agar manajer mampu menjalankan aktivitasnya secara jujur dan melaporkan apa adanya pada pihak-pihak yang berkepentingan. Karena hal itu timbul dari dalam diri manajer maka apa yang dilakukan manajer adalah atas kesadaran pribadi bukan paksaan dari luar yang berupa aturan-aturan dan jika dilanggar akan ada sanksinya. Jika sikap baik itu muncul karena kesadaran dari dalam diri seorang manajer maka hal itu akan jauh lebih baik dibandingkan manajer itu berbuat baik karena takut melanggar aturanaturan yang jika nanti terbukti akan mendapatkan sanksi, tindakan manajer yang 
didasarkan pada hanya ingin taat pada aturan, maka kemungkinan dia untuk melanggar dan melakukan moral hazard tetap ada, karena dia akan berpikir selama tidak ketahuan maka dia tidak akan terkena sanksi. Berbeda dengan kalau tindakan manajer itu didasarkan pada perilaku etis yang melekat pada pribadi seorang manajer, maka setiap tindakan dan keputusannya akan selalu merujuk pada etika dan norma-norma yang ada, dan secara otomatis seorang manajer akan terhindar dari perbuatan moral hazard.

Sehingga bisa disimpulkan bahwa peran etika dalam hal ini sangat besar pengaruhnya terhadap setiap keputusan yang diambil oleh manajer, dengan berpegang pada etika dan norma-norma yang ada maka dalam bertindak manajer akan dikontrol oleh hati nuraninya. Karena kebenaran dan kejujuran akan selalu dikatakan oleh hati nurani, maka dalam setiap tindakan akan selalu dirujuk pada hati nurani, sehingga hal itu akan memposisikan seorang manajer dalam tindakan yang selalu benar bagi banyak orang.

\section{DAFTAR PUSTAKA}

Barefield, R. M., \& E, E. Comiskey. (1972). The Smoothing Hypothesis: An Alternatif Test. The Accounting Review, 291-298.

Bartov, E. (1993). The Timing of Asset Sales and Earnings Manipulation. The Accounting Review, 68, 840-855.

Beattie, V., S, Brown., D, Ewers., B, John., S, Mason., D, Thomas., \& M, Tuner. (1994). Extraordinary Items and Income Smoothing: A Positif Accounting Approach. Journal of Business Finance and Accounting, 21 (6), 791-811. 
Beneish, M. D. (1997). Detecting GAAP Violation: Implications for Assesing Earnings Management among Firms with Extreme Financial Performance. Journal of Accounting and Public Policy, 16, 271-309.

Beneish, M. D. (1999) Incentives and Pinalties Related to Earnings Overstatements that Violate GAAP. The Accounting Review, 74 (4), 425458.

Brayshaw., R, E., \& A, E. K. Eldin. (1989). The Smoothing Hypothesis and the Role of Exchange Differences. Journal of Business Finance and Accounting, 16 (5), 621-633.

Carlson, S. J., \& C, T. Bathala. (1997). Ownership Differences and Firm's Income Smoothings Behaviour. Journal of Business Finance \& Accounting, 24 (2), 179-196.

Claessens, S., S, Djankov., J, P. H. Fan., \& L, H. P. Lang. (2000). Expropriation of Minority Shareholders: Evidence from East Asia. Working Paper.

Copeland, R. M. (1968). Income Smoothing. Journal of Accounting Research, Empirical Research in Accounting, Selected Studies 6 (Supplement), 101116.

Cornett, M. M., J, Marcuss, Saunders., \& Tehranian, H. (2006). Earnings Management, Corporate Governance, and True Financial Performance [On-line] Available http://papers.ssrn.com.

Dascher, P. E., \& R, E. Malcolm. (1970). A Note on Income Smoothing in the Chemical Industry. Journal of Accounting Research, 253-259.

Dechow, P. M., R,G. Sloan., \& A, P. Sweeney. (1995). Detecting Earnings Management. The Accounting Review, 70, 193-225.

Dechow, P. M., \& D, J. Skinner. (2000). Earnings Management: Reconciling Vies of Accounting Academic, Practitioners, and Regulators. Accounting Horizons, 14, 235-250.

Eisenhardt, Kathleem. M. (1989). Agency Theory: An Assesment and Review. Academy of Management Review, 14, 57-74.

Fisher, M., \& K, Rosenzweig. (1995). Attitude of Students and Accounting Practitioners Concerning The Ethical Acceptability of Earnings Management. Journal of Business Ethics, 14, 433-444.

Gideon, S. B. Boediono. (2005). Kualitas Laba: Studi Pengaruh Mekanisme Corporate Governace dan Dampak Manajemen Laba dengan Menggunakan Analisis Jalur. Simposium Nasional Akuntansi VIII. Solo. 
Givoly, D., \& J, Ronen. (1981). Smoothing Manifestations in Fourth Quarter Results of Operations: Some Empirical Evidence. Abacus. 17 (2), 174193.

Irfan, Ali. (2002). Pelaporan Keuangan dan Asimetri Informasi dalam Hubungan Agensi. Lintasan Ekonomi, XIX (2).

Jensen, Michael. C., \& W, H. Meckling. (1976). Theory of The Firm: Managerial Behavior, Agency Cost and Ownership Structure. Journal of Financial Economics, 3, 305-360.

Keraf \& Imam. (1995). Urgensi Etika Bisnis dalam Dunia Bisnis di Indonesia. Jurnal Riset Akuntansi Indonesia, 2 (1), 41-43.

Keraf, A. Sonny. (1998). Etika Bisnis: Membangun Citra Bisnis sebagai Profesi Luhur. Yogyakarta: Kanisius.

Keraf, A. Sony. (2001). Etika Bisnis - Tuntutan Dan Relevansinya, Cetakan Keempat. Yogyakarta: Kanisius.

Kirchheimer, H.W. (1968). Discussion of Income Smoothing. Journal of Accounting Research, Empirical Research in Accounting, Selected Studies 6 (Supplement), 117-119.

Michelson, S. E., J, Jordan. Wagner., \& C, W. Wooton. (1995). A Market based Analysis of Income Smoothing. Journal of Business Finance \& Accounting, 22(8), 1179-1193.

Moses, O. D. (1987). Income Smoothing and Incentive: Empirical Tests Using Accounting Changes. The Accounting Review, 62 (2), 358-377.

Neil, J. D., S, G. Pourciau., \& T, F. Schaefer. (1995). Accounting Method Choice and IPO Valuation. Accounting Horizons, 9 (3), 68-80.

Pusat Pembinaan dan Pengembangan Bahasa. (1998). Kamus Besar Bahasa Indonesia. Jakarta: Balai Pustaka.

Rest, J. R. (1986). Moral Development: Advances in Research and Theory, New York, NY: Praegar.

Richardson, Vernon. J. (1998). Information Asymmetry an Earnings Management : Some Evidence. Working paper, 30 Maret.

Schiff, M. (1968). Discussion of Income Smoothing, Journal of Accounting Research, Empirical Research in Accounting, Selected Stidies 6 (Supplement), 120-121. 
Schipper, Katherine. (1989). Comentary Katherine on Earnings Management. Accounting Horizon.

Scott, William. R. (2000). Financial Accounting Theory. Second Edition. Canada: Prentice-Hall Canada Inc.

Siagian, SP. (1996). Etika Bisnis, Seri Manajemen No 177, PT. Pustaka Binaman Pressindo.

Soewardi, Herman. (2001). Roda Berputar Dunia Bergulir. Bandung: Bakti Mandiri.

Stolowy, H., \& G, Breton. (2000). A Review of Research on Accounts Manipulation. Working Paper for Presentation at the 23-nd Annual Congress of the European Accounting Association.

Utama, Siddharta. (2000). "Teori dan Riset Akuntansi Positif: Suatu Tinjauan Literatur." Jurnal Ekonomi dan Bisnis Indonesia, 15 (1), 83-96.

Wibisono, Haris. (2004). Pengaruh Earnings Management Terhadap Kinerja di Seputar SEO. Tidak dipublikasikan Tesis S2, Magister Sains Akuntansi Universitas Diponegoro, Semarang. 